Бекеева Саулемай Айдаровна

к.б.н., доцент, с.н.с лаборатории регламентации РГКП «Республиканский научно-исследовательский институт по охране труда Министерства труда и социальной защиты населения Республики Казахстан», г. Астана E-mail: nauka@rniiot.kz ORCID ID: 0000-0002-6359-5940

\title{
ОЦЕНКА УМСТВЕННОЙ РАБОТОСПОСОБНОСТИ РАБОТНИКОВ ПРИ ВАХТОВОМ МЕТОДЕ ОРГАНИЗАЦИИ ТРУДА
}

Bekeyeva Saulemay Aydarovna Ph.D., Associate Professor, Senior Researcher, Laboratory of Regulation Republican State Enterprise "Republican Research Labor Protection Institute of the Ministry of Labor and social protection of the population Republic of Kazakhstan", Astana E-mail:nauka@rniiot.kz ORCID ID: 0000-0002-6359-5940

\section{ESTIMATION OF THE MENTAL WORKING CAPACITY OF EMPLOYEES UNDER THE WATCH METHOD OF LABOR ORGANIZATION}

Annotation. In the study of workers of the gold ore processing plant in the dynamics of work shifts and shift work period, it was found that the interchangeable nature of labor leads to disruption of habitual biorhythms, more rapid development of fatigue and reduced mental performance. The reduction of physiological indicators for certain hours of work shifts justifies the need for maintaining regulated breaks in order to prevent professionally caused diseases and reduce the risk of industrial accidents.

Keywords: work shift, shift work, mental performance, occupational risk.

Аннотация. При исследовании работников фабрики по переработке золотосодержащей руды в динамике рабочих смен и вахтового периода работы было установлено, что сменный характер труда приводит к нарушению привычных биоритмов, более быстрому развитию утомления и снижения умственной работоспособности. Понижение физиологических показателей по определенным часам рабочих смен обосновывает необходимость ведения регламентированных внутрисменных перерывов с иелью профилактики профессионально обусловленных заболеваний и снижения риска несчастных случаев на производстве.

Ключевые слова: динамика рабочей смены, вахтовая работа, умственная работоспособность, профессиональный риск.

Известно, что к недостаткам вахтового метода труда относится интенсивный труд во время вахтового периода, который сопровождается хроническим напряжением всех физиологических систем организма. В частности при сменной организации труда нарушаются суточные биологические ритмы человека, что способствует быстрому развитию утомления [1-5]. Также в исследованиях авторов установлено, что у работников между показателями, отражающими функциональное состояние организма, продолжительностью смены и производственными факторами существует достоверная связь, а именно, продолжительность смены, влияла на состояние дыхательной, сердечнососудистой и центральной нервной систем [6-8]. Кроме того, при сменной работе повышается риск несчастных случаев на производстве в большей степени, чем при штатном режиме труда. По данным Комитета по статистике Министерства национальной экономики РК, в 2016 году доля пострадавших на производстве при сменном режиме

Оценка умственной работоспособности
Материалы Международной практической интернет-конференции «Актуальные Проблемы Науки» 
труда составляет более 50 \% от общего количества пострадавших при выполнении трудовых обязанностей. Следовательно, проблема вахтовой работы и связанных с ней процессов утомления умственной работоспособности и риска возникновения патологических состояний работающих представляется весьма актуальной.

В исследовании приняли участие 94 рабочих мужчин. Производственную сферу изучаемого предприятия представили рабочие таких профессии как машинист мельницы, машинист погрузочно-доставочной машины, мастер смены, электрик, аппаратчик, бункеровщик и др. - 79 человек, непроизводственную сферу (15 человек) представляли инженерно-технические работники (ИТР), не находящиеся в течение рабочего дня в прямом контакте с вредными производственными факторами, и работающие в штатном режиме. Исследование функционального состояния организма работников включало оценку состояния центральной нервной системы в динамике дневной и ночной смен в начале и конце вахтового периода по показателям умственной работоспособности (таблица Бурдона-Анфимова): коэффициента точности выполнения задания (А); коэффициент умственной продуктивности (P); объема зрительной информации (Q); скорость переработки информации (S); - показатель устойчивости внимания (УВН). Полученные материалы обработаны на персональном компьютере с привлечением пакета статистических программ с непараметрическими методами биологической статистики с применением пакета программных приложений Microsoft Excel XP и интегрированного пакета статистических программ STATISTICA 10.0.

Помимо воздействий вредных производственных факторов, состояние организма работников зависит от применяемых режимов труда и отдыха при сменной организации труда. Так, исследованиями установлено, что при штатном режиме труда у ИТР в динамике рабочего дня наблюдалось статистически значимое понижение коэффициента умственной продуктивности, объема зрительной информации, скорости переработки информации $(\mathrm{p}<0,05)$, что свидетельствует о недостаточности ночного отдыха. Повышение этих показателей в динамике рабочего дня показывает на успешность процесса врабатывания.

Начало рабочей недели. Исследованиями функционального состояния у работников 1 смены с ночным временем установлено статистически значимое понижение значений коэффициента точности выполнения задания, коэффициента умственной продуктивности, скорости переработки информации и показателя устойчивости внимания перед началом рабочей смены $(\mathrm{p}<0,05)$ у этих же работников. Данные изменения показывают на недостаточность межсменного отдыха. В результате врабатывания у работников в динамике рабочей смены нормализуются показатели умственной работоспособности. Статистически значимые изменения показателей общей работоспособности и выносливости не обнаружили (таблица 1).

Таблица 1

Оиенка умственной работоспособности работников фабрики в динамике 8 часовой 1смены с ночным временем (с 00.00 ч - 8.00 ч.), начало рабочей недели, Ме (Q25;Q75)

\begin{tabular}{|l|l|l|l|l|l|}
\hline \multicolumn{1}{|c|}{$\begin{array}{c}\text { Наименование } \\
\text { показателя }\end{array}$} & \multicolumn{5}{|c|}{ Этапы исследования в динамике рабочей смены } \\
\hline $\begin{array}{l}\text { Умственная работо- } \\
\text { способность }\end{array}$ & \multicolumn{1}{|c|}{1} & \multicolumn{1}{|c|}{2} & \multicolumn{1}{c|}{4} & \multicolumn{1}{c|}{5} \\
\hline А (в усл.ед.) & 0,91 & 0,97 & $0,97(0,96 ; 0,97)$ & $0,97(0,95 ; 0,98)$ & $0,98(0,97 ; 0,99)$ \\
& $(0,87 ; 0,96)^{*}$ & $(0,93 ; 0,98)$ & $361,06(325,04 ;$ & $360,27(325,14 ;$ & 377,29 \\
Р (в усл.ед.) & 314,80 & 371,41 & $412,84)$ & $430,95)$ & $(340,70 ;$ \\
& $(273,41 ;$ & $(334,80 ;$ & $220,82(207,17 ;$ & $220,82(203,60 ;$ & $441,39)$ \\
& $378,05)^{*}$ & $412,74)$ & $251,69)$ & $251,69)$ & 227,65 \\
\hline
\end{tabular}

Оценка умственной работоспособности
Материалы Международной практической интернет-конференции «Актуальные Проблемы Науки» 


\begin{tabular}{|l|l|l|l|l|l|}
\hline Q (в бит) & 221,12 & 229,13 & $1,77(1,69 ; 2,03)$ & $1,76(1,58 ; 1,96)$ & $(210,73 ;$ \\
& $(180,45 ;$ & $(213,70 ;$ & $138,33(112,00 ;$ & 91,89 & $266,53)$ \\
S (в бит/с) & $239,52)$ & $251,69)$ & $163,25)$ & $(68,60 ;$ & $1,85(1,68 ; 2,17)$ \\
& 1,51 & 1,82 & & $182,00)^{*}$ & $224,50(125,75 ;$ \\
УВН (в усл.ед.) & $(1,29 ; 1,85)^{*}$ & $(1,62 ; 2,03)$ & & & $364,00)$ \\
& $42,80(27,78 ;$ & 119,50 & & & \\
& $98,67)^{*}$ & $(53,00 ;$ & & & \\
\hline
\end{tabular}

Примечание. Данные представлены в виде Ме (Q25;Q75);* - знак показывает статистически значимые изменения при $p<0,05 ; A$ - коэффищиент точности выполнения задания; $P$ коэффициент умственной продуктивности; $Q$ - объем зрительной информации; $S$ - скорость переработки информачии; УВН - показатель устойчивости внимания;

У работников-производственников 2 смены перед работой обнаружены статистически значимое понижение значений коэффициента умственной продуктивности, объема зрительной информации, скорости переработки информации $(\mathrm{p}<0,05)$, что связано недостаточностью межсменного отдыха. Также, у этих работников статистически значимое понижение данных показателей обнаружено во второй половине рабочей смены $(\mathrm{p}<0,05)$, что свидетельствует о состоянии усталости. В этом состоянии снижается способность оценивать сигналы опасности, в результате повышается риск травматизма на производстве. С целью восстановления функционального состояния работников рекомендуется в этот период рабочей смены предоставлять работникам кратковременный перерыв, в результате такого подхода снижается риск травматизма на производстве. У работников-производственников 3 смены наблюдалось изменения значений коэффициента умственной продуктивности, объема зрительной информации, скорости переработки информации, обнаружены в середине первой половины рабочей смены, что характеризует усталость работников (таблица 2).

Таблица 2

Оиенка функиионального состояния организма работников фабрики в динамике 8 часовой 3 смены с вечерним временем (16.00 ч - 00.00 ч), начало рабочей недели, Me (Q25;Q75)

\begin{tabular}{|l|l|l|l|l|l|}
\hline \multicolumn{1}{|c|}{$\begin{array}{c}\text { Наименование } \\
\text { показателя }\end{array}$} & \multicolumn{5}{|c|}{ Этапы исследования в динамике рабочей смены } \\
\hline $\begin{array}{l}\text { Умственная рабо- } \\
\text { тоспособность }\end{array}$ & \multicolumn{1}{|c|}{1} & \multicolumn{1}{|c|}{2} & \multicolumn{1}{c|}{3} & \multicolumn{1}{c|}{5} \\
\hline A (в усл.ед.) & 0,91 & 0,97 & $0,95(0,93 ; 0,98)$ & $0,88(0,87 ; 0,98)$ & $0,95(0,93 ; 0,98)$ \\
& $(0,88 ; 0,95)^{*}$ & $(0,91 ; 0,97)$ & $356,87(254,57 ;$ & $354,49(247,00 ;$ & $362,96(318,30 ;$ \\
P (в усл.ед.) & 334,80 & 285,68 & $404,48)$ & $384,05)$ & $402,61)$ \\
& $(230,86 ;$ & $(215,86 ;$ & $219,04(161,76 ;$ & $248,42(146,62 ;$ & $225,57(193,51 ;$ \\
& $378,38)$ & $320,04)^{*}$ & $254,36)$ & $257,03)$ & $263,56)$ \\
Q (в бит) & 213,70 & 173,92 & $1,74(1,23 ; 1,98)$ & $1,80(1,22 ; 2,01)$ & $1,75(1,54 ; 1,94)$ \\
& $(173,33 ;$ & $(141,28 ;$ & 80,98 & 120,40 & 72,00 \\
S (в бит/с) & $250,50)$ & $251,69)^{*}$ & $(54,50 ;$ & $(30,14 ; 247,00)$ & $(49,00 ; 163,00)$ \\
& 1,57 & 1,40 & $221,50)$ & & \\
уВН (в усл.ед.) & $(1,06 ; 1,82)$ & $(1,08 ; 1,44) *$ & & & \\
& 42,38 & $108,50(59,50 ;$ & & & \\
& $(29,67 ;$ & $146,50)$ & & & \\
\hline
\end{tabular}

Конеи рабочей недели. У работников 1 смены с ночным временем (в середине первой половины рабочей смены) установлено понижение объема зрительной информации и показателя устойчивости внимания ( $<0,05)$ (таблица 3 ).

Оценка умственной работоспособности
Материалы Международной практической интернет-конференции «Актуальные Проблемы Науки» 
Таблииа 3

Оиенка функиионального состояния организма работников фабрики в динамике 8 часовой 1 смены с ночным временем (00.00 ч - 8.00 ч), конеи рабочей недели, Мe (Q25;Q75)

\begin{tabular}{|l|l|l|l|l|l|}
\hline \multicolumn{1}{|c|}{$\begin{array}{c}\text { Наименование } \\
\text { показателя }\end{array}$} & \multicolumn{5}{|c|}{ Этапы исследования в динамике рабочей смены } \\
\hline $\begin{array}{l}\text { Умственная работо- } \\
\text { способность }\end{array}$ & \multicolumn{1}{|c|}{1} & \multicolumn{1}{|c|}{2} & \multicolumn{1}{c|}{4} & \multicolumn{1}{|c|}{5} \\
\hline А (в усл.ед.) & 0,98 & 0,96 & $0,98(0,96 ; 1,00)$ & $0,99(0,97 ; 1,00)$ & 0,99 \\
& $(0,93 ; 0,98)$ & $(0,91 ; 0,99)$ & $343,97(303,84 ;$ & $353,19(318,00 ;$ & $(0,95 ; 0,99)^{*}$ \\
P (в усл.ед.) & 357,39 & 333,32 & $403,88)$ & $420,28)$ & $374,55(303,55 ;$ \\
& $(313,61 ;$ & $(271,83 ;$ & $214,59(193,81 ;$ & $216,07(188,76 ;$ & $384,34)$ \\
Q (в бит) & $427,14)$ & $404,58)$ & $246,34)$ & $251,69)$ & $226,16(188,76 ;$ \\
& 216,37 & 208,65 & $1,70(1,45 ; 1,98)$ & $1,73(1,57 ; 2,07)$ & $238,03)$ \\
S (в бит/с) & $(194,70 ;$ & $(172,14 ;$ & $240,00(100,83 ;$ & $343,00(140,00 ;$ & $1,83(1,48 ; 1,90)$ \\
& $271,57)$ & $250,20)^{*}$ & $382,00)$ & $424,00)$ & $327,00(79,50 ;$ \\
уВН (в усл.ед.) & 1,76 & 1,62 & & & $388,00)^{*}$ \\
& $(1,53 ; 2,03)$ & $(1,27 ; 1,98)$ & & & \\
\hline
\end{tabular}

У работников 2 смены перед рабочей смены наблюдалось понижение объема зрительной информации, скорости переработки информации и показателя устойчивости внимания $(\mathrm{p}<0,05)$, что характеризует недостаточность межсменного отдыха. У этих же работников установлено наблюдалось понижение показателя устойчивости внимания в первой половине рабочей смены, что характеризует усталость ( $<0,05)$ (таблица 4).

Таблица 4

Оиенка функционального состояния организма работников фабрики в динамике 8 часовой 2 смены с дневным временем (08.00 ч - 16.00 ч), конеи рабочей недели, Ме (Q25;Q75)

\begin{tabular}{|l|l|l|l|l|l|}
\hline \multicolumn{1}{|c|}{$\begin{array}{c}\text { Наименование } \\
\text { показателя }\end{array}$} & \multicolumn{5}{|c|}{ Этапы исследования в динамике рабочей смены } \\
\hline $\begin{array}{l}\text { Умственная работо- } \\
\text { способность }\end{array}$ & \multicolumn{1}{|c|}{1} & \multicolumn{1}{|c|}{2} & \multicolumn{1}{c|}{4} & \multicolumn{1}{|c|}{5} \\
\hline А (в усл.ед.) & 0,95 & 0,96 & $0,98(0,96 ; 0,99)$ & $0,94(0,92 ; 0,97)$ & $0,98(0,93 ; 0,99)$ \\
& $(0,94 ; 0,99)$ & $(0,95 ; 0,98)$ & $378,64(307,16 ;$ & $343,00(242,30 ;$ & $364,71(300,64 ;$ \\
Р (в усл.ед.) & 299,39 & 345,47 & $405,40)$ & $443,70)$ & $429,23)$ \\
& $(262,05 ;$ & $(342,00 ;$ & $225,86(188,76 ;$ & $214,59(156,71 ;$ & $220,82(193,51 ;$ \\
& $343,00)$ & $405,40)$ & $251,69)$ & $272,46)$ & $257,03)$ \\
Q (в бит) & 179,86 & 213,70 & $1,87(1,50 ; 1,98)$ & $1,67(1,17 ; 2,18)$ & $1,79(1,45 ; 2,12)$ \\
& $(166,21 ;$ & $(207,17 ;$ & $233,00(84,80 ;$ & $79,38(44,00 ;$ & $186,00(54,20 ;$ \\
S (в бит/с) & $203,60)^{*}$ & $251,69)$ & $401,00)$ & $114,75)^{*}$ & $433,00)$ \\
& 1,48 & 1,70 & & & \\
УВН (в усл.ед.) & $(1,27 ; 1,70)^{*}$ & $(1,66 ; 1,98)$ & & & \\
& $77,00(56,00 ;$ & $84,80(72,00 ;$ & & & \\
\hline
\end{tabular}

У работников 3 смены в динамике рабочей смены наблюдалось повышение показателя устойчивости внимания $(\mathrm{p}<0,05)$, что характеризует состояние хронической усталости в конце рабочей недели. Кроме того, у этих же работников перед началом рабочей смены выявлены статистически значимое понижение объема зрительной информации, скорости переработки информации и показателя устойчивости внимания, что характеризует недостаточность межсменного отдыха (таблица 5).

Оценка умственной работоспособности
Материалы Международной практической интернет-конференции «Актуальные Проблемы Науки» 
Оиенка функиионального состояния организма работников фабрики в динамике 8 часовой 3 смены с вечерним временем (16.00 ч - 00.00 ч), конеи рабочей недели, Me (Q25;Q75)

\begin{tabular}{|l|l|l|l|l|l|}
\hline \multicolumn{1}{|c|}{$\begin{array}{c}\text { Наименование } \\
\text { показателя }\end{array}$} & \multicolumn{5}{|c|}{ Этапы исследования в динамике рабочей смены } \\
\hline $\begin{array}{l}\text { Умственная работо- } \\
\text { способность }\end{array}$ & \multicolumn{1}{|c|}{1} & \multicolumn{1}{|c|}{2} & \multicolumn{1}{|c|}{4} & \multicolumn{1}{|c|}{5} \\
\hline А (в усл.ед.) & 0,95 & 0,96 & $0,96(0,92 ; 0,99)$ & $0,95(0,85 ; 0,99)$ & $0,97(0,93 ; 0,98)$ \\
& $(0,77 ; 0,99)$ & $(0,89 ; 0,98)$ & $395,83(356,96 ;$ & $405,40(370,95 ;$ & $401,31(378,56 ;$ \\
P (в усл.ед.) & 338,99 & 404,26 & $442,69)$ & $506,99)$ & $514,89)$ \\
& $(280,71$ & $(339,18 ;$ & $248,12(220,52 ;$ & $255,84(229,72 ;$ & $244,86(234,77 ;$ \\
Q (в бит) & $; 383,18)$ & $459,56)$ & $266,53)$ & $309,86)$ & $327,37)$ \\
& 214,88 & 248,72 & $1,92(1,74 ; 2,19)$ & $1,99(1,83 ; 2,46)$ & $1,97(1,88 ; 2,45)$ \\
& $(207,76 ;$ & $(222,60 ;$ & 88,17 & 91,60 & $124,25(65,85 ;$ \\
S (в бит/с) & $257,03)^{*}$ & $316,98)$ & $(43,57 ;$ & $(26,18 ;$ & $194,50)$ \\
& 1,65 & 1,99 & $283,75)^{*}$ & $402,00)^{*}$ & \\
уВН (в усл.ед.) & $(1,38 ; 1,78)^{*}$ & $(1,63 ; 2,25)$ & & & \\
& $89,17(16,57 ;$ & $96,75(39,77 ;$ & & & \\
\hline
\end{tabular}

Исследования умственной работоспособности работников фабрики в динамике рабочих смен и вахтового периода (начало и конец) установили общие закономерности влияния применяемых режимов труда и отдыха на организм работников в целом по изучаемым структурным подразделениям и в разрезе изучаемых профессий. Понижение показателей умственной работоспособности у работников дневной и ночной смен в начале и конце вахтового периода показывает на физиологическую неадекватность биологическим ритмам организма человека. Начало работы дневной смены с 7.00 ч определяет необходимость подъема от ночного сна в интервале 4.30 ч - 5.00 ч, что нарушает генетически заложенные в организме ритмы сна. Начало работы дневной смены с 8.00 ч не вызывает отрицательных изменений в организме человека. Понижение физиологических показателей по определенным часам рабочих смен обосновывает необходимость ведения регламентированных внутрисменных перерывов на основании пункта 1 ст. 82 ТК РК.

С целью профилактики усталости, также важное значение имеет суммированный учет ночного времени работы, который необходимо вести на каждого работника индивидуально с целью профилактики усталости, количество ночного времени не должно превышать $1 / 3$ от общего количества отработанных часов за год. Рекомендуется при планировании графиков вахт придерживаться длительности вахтового периода не более 15 суток с целью профилактики профессионально обусловленных заболеваний и снижения риска несчастных случаев на производстве.

Таким образом, воздействие факторов условий труда на рабочих местах, не отвечающим гигиеническим нормативам, создает предпосылки для функциональных отклонений в состоянии здоровья работника, и является потенциальным фактором профессионального риска. Та как полностью исключить риски в процессе трудовой деятельности нельзя, одним из приоритетных направлений прогнозирования и снижения травматизма и профессиональных заболеваний является разработка программ мероприятий, направленных на снижение воздействий вредных производственных факторов.

\section{СПИСОК ЛИТЕРАТУРЫ}

1. Онаев С.Т., Абитаев Д.С., Шаметеков И.М., Балаева Е.А., Шадетова А.Ж. Функциональное состояние организма работников, занятых на производстве с особыми формами

Оценка умственной работоспособности
Материалы Международной практической интернет-конференции «Актуальные Проблемы Науки» 
организации труда // Гигиена труда и медицинская экология. - 2009. - №3 (24). - С. 41 50.

2. Сарычев А.С. Характеристика адаптивных реакций организма вахтовых рабочих в условиях заполярья: Автореф. дис. ...Д - ра мед. наук. - Архангельск, 2012. - 35 с.

3. Дикая Л. Г., Кутлубаева Р.М. Социально-психологические факторы трансформации личности профессионала при вахтовом режиме работы на Крайнем Севере // Организационная психология и психология труда. - 2017. - Т. 2. - № 1. - С.91-112.

4. Сорокин Г.А., Фролова Н.М. Физиолого-гигиеническое обоснование длительности смены (8 и 12 часов) при непрерывном производстве // Медицина труда и промышленная экология. - 2013. - № 8. - С. 7-12.

5. Сорокин Г.А., Фролова Н.М. Физиолого-гигиеническое обоснование длительности смены (8 и 12 часов) при непрерывном производстве // Медицина труда и промышленная экология. - 2013. - № 8. - С. 7-12.

6. Onaev S.T., Balaeva E.A., Ismailova A.A., Kurmangalieva D.S., Shadetova A.Zh.. Psychophysiologic criteria determining performance in shift team workers. Meditsina truda $i$ promyshlennaya ekologiya. 2012; 7: 38-40. (in Russian).

7. Крекешева Т.И., Молдашова Г.А. Роль медико-профилактических мероприятий в системе управления охраной труда. «Интернаука», №30. 2017.-С.38.

8. Еселханова Г.А., Каминская Г. А., Шайхы Р. Т.Международные подходы по обеспечению безопасных условий труда. Международный центр инновационных исследований «Омега сайнс», тенденции и перспективы развития науки XXI века. Екатеринбург, 2015.-С.47 